\title{
Atividade alelopática dos lixiviados de Asemeia extraaxillaris (Polygalaceae) sobre o crescimento de Ipomoea cordifolia
}

SILVA, C.B. ${ }^{*}$; OLIVEIRA, M. ${ }^{\prime}$; DIAS, J.F.1; ZANIN, S.M.W."; SANTOS, G.O.2; CÂNDIDO, A.C.S. ${ }^{2}$; PERES, M.T.L.P.3; SIMIONATTO, E.4; MIGUEL, O.G.'; MIGUEL, M.D.1.

'Universidade Federal do Paraná, Departamento de Farmácia, Av. Lothario Meissner, 632, Caixa Postal 19081, Jardim Botânico, CEP 80210-170, Curitiba- PR. ' Universidade Federal do Paraná, Departamento de Botânica, Rua Francisco Heráclito dos Santos, 210, Caixa Postal 19031, Centro Politécnico, CEP 81531-900, CuritibaPR. ${ }^{3}$ Universidade Federal de Mato Grosso do Sul, Departamento de Hidráulica e Transportes, Caixa Postal 549, CEP 79070-900, Campo Grande- MS. 4Universidade Estadual de Mato Grosso do Sul, Departamento de Química, Rua 275, Rua Emilio Mascolli, centro, 79950-000, Naviraí- MS. *Autor para correspondência: cris. mpj@gmail.com

RESUMO: O objetivo desse trabalho foi avaliar a atividade alelopática dos lixiviados das raízes e folhas secas de Asemeia extraaxillaris sobre o crescimento de corda de viola Ipomoea cordifolia em casa de vegetação, para avaliação dos efeitos sobre o estresse oxidativo. Nos bioensaios foram utilizadas três concentrações $(0,25-5,00$ e 10,00 g) e um controle, com quatro repetições de 10 plantas, cultivadas em solo durante 30 dias. Os lixiviados possuem ação alelopática e o maior efeito foi verificado para o pó das raizes. O efeito inibitório foi dose-dependente e o aumento do estresse oxidativo foi observado pelos níveis da catalase, peroxidase, superóxido dismutase, glutationa redutase, peroxidação lipídica e síntese de formazan. Concluiu-se que $A$. extraaxillaris possui substâncias capazes de afetar a emergência, o crescimento e o estresse oxidativo de I. cordifolia.

Palavras chave: estresse oxidativo, lixiviação, fitoherbicida, mentol-do-campo, corda-de-viola.

\begin{abstract}
Allelopathic activity of leachates from Asemeia extraaxillaris (Polygalaceae) on the growth of Ipomoea cordifolia. The purpose of this article is to assess the allelopathic activity of leachates from the roots and dried leaves of Asemeia extraaxillaris on the germination and growth of corda de viola (Ipomoea cordifolia) in a greenhouse, and evaluate its effect on oxidative stress. For the bioassays, three concentrations $(0.25,5.00$, and $10.00 \mathrm{~g})$ and one control were used, with four replications of 10 plants, cultivated in soil for 30 days. The leachates exhibited allelopathic action, and the greatest effect was found in the root powder. The inhibitory effect was dose-dependent and the increase in oxidative stress was observed by the levels of catalase, peroxidase, superoxide dismutase, glutathione reductase, lipid peroxidation, and formazan synthesis. It was affirmed that $A$. extraaxillaris contains substances capable of affecting seedling emergence, growth, and oxidative stress in I. cordifolia.
\end{abstract}

Keywords: oxidative stress, leachates, phyto herbicide, mentol-do-campo, corda-de-viola.

\section{INTRODUÇÃO}

Asemeia extraaxillaris ocorre no Paraguai, Argentina e Brasil: Paraná, Santa Catarina, Rio Grande do Sul e Mato Grosso do Sul, sendo amplamente utilizada pela população do Pantanal (Pott \& Pott, 1994). Esta espécie é encontrada em beiras de estradas alteradas por queimadas, em campos limpos, arbustivos, solos secos ou úmidos, em morros graníticos. Floresce e frutifica de agosto a abril (Lüdtke \& Aguiar 2008). Recentemente
Silva et al. (2013) demonstraram que o óleo volátil presente nas raízes possui efeito alelopático sobre a brachiária, inibindo a germinação e crescimento inicial desta espécie.

As substâncias alelopáticas produzidas por plantas são liberadas no ambiente através dos processos de exsudação radicular, lixiviação, volatilização ou decomposição, influenciando de forma favorável ou desfavorável o crescimento e 
desenvolvimento de sistemas biológicos e agrícolas (Macias et al., 2000). Todos esses mecanismos estão sujeitos a constantes modificações que se expressam na capacidade adaptativa como conseqüência de sua interação com o meio ambiente (Oliveros-Bastidas et al., 2009).

No campo, os efeitos alelopáticos negativos sobre a germinação levam à desuniformidade da cultura, uma vez que os aleloquímicos podem proporcionar estresse oxidativo, formando espécies reativas de oxigênio, como $\circ \mathrm{H}_{2} \mathrm{O}_{2}$, que atua de forma direta ou como sinalizador nos processos de degradação celular causando danos em processos fisiológicos e alterando o desenvolvimento inicial das plântulas (Almeida et al., 2008).

Muitas espécies de plantas daninhas são de difícil controle em culturas de campo, devido à grande produção de sementes e sua longa viabilidade. Neste aspecto, Ipomoea cordifolia, uma erva daninha tropical e subtropical, que é vulgarmente conhecida como corda- de- viola, é um eudicotiledônea da família Convolvulaceae. É muito freqüente observar a presença desta espécie em culturas de soja (Glycine Max), e sua presença pode levar a uma perda na produção de grãos várias (Holm et al., 1997).

A maioria das pesquisas em alelopatia refere-se apenas ao efeito do aleloquímico sobre a germinação e o crescimento da planta-teste, não considerando os eventos celulares relacionados às mudanças fisiológicas no sistema da planta, ou ainda os seus efeitos no crescimento de plantas daninhas.

Fundamentada nestes fatos e respeitando os ideais da agricultura sustentável, a qual defende o uso racional de recursos naturais, a Fitoquímica também é norteada pela prospecção de aleloquímicos capazes de retardar significativamente o desenvolvimento de plantas invasoras e com potencial suficiente para serem utilizados em substituição aos defensivos agrícolas convencionais (Nishimura et al., 1984; Pires et al., 2001).

O objetivo do presente trabalho foi avaliar a atividade alelopática dos lixiviados das raízes e folhas de $A$. extraaxillaris sobre o crescimento de Ipomoea cordifolia, e se há um aumento no estresse oxidativo após 30 dias de cultivo em casa de vegetação, com a finalidade de investigar preliminarmente a aplicabilidade de lixiviados de $A$. extraaxillaris para o controle de I. cordifolia.

\section{MATERIAL E MÉTODOS}

Cerca de 20 indivíduos de Asemeia extraaxillaris, medindo cerca de $10-35 \mathrm{~cm}$ foram coletados no Pantanal de Mato Grosso do Sul, entre os meses de abril e maio de 2010 , sob as Coordenadas $19^{\circ} 33^{\prime} 97^{\prime \prime} \mathrm{S} 057^{\circ} 02^{\prime} 20.7^{\prime \prime} \mathrm{W}$, e um exemplar da espécie foi identificado e depositado nos herbários CGMS e MBM sob os números 334776 e 357010 , respectivamente. Após a coleta, os indivíduos foram levados à base de estudos do Pantanal e secos em estufa de ventilação forçada em temperatura de $30^{\circ} \mathrm{C}$, e em seguida, a parte aérea (folhas) e subterrânea (raízes) foi separada e moída em moinho de facas e armazenada até o momento dos ensaios.

O solo utilizado nos ensaios foi submetido análises físico- químicas, realizadas no laboratório de solos da UFGD e os resultados se encontram na tabela 1, onde os parâmetros indicadores da qualidade do solo mostram que este apresenta condições adequadas para o uso.

Nos ensaios em casa de vegetação, cada vaso plástico $(9,0 \times 8,0 \mathrm{~cm}$, diâmetro e altura), recebeu $200 \mathrm{~g}$ de solo e em seguida 5 sementes

TABELA 1. Características químicas e físicas' ${ }^{1}$ do solo utilizado nos ensaios em casa de vegetação.

\begin{tabular}{|c|c|c|c|c|c|c|c|c|}
\hline & Argila & $\mathrm{MO}$ & $\mathrm{pH}$ & $P$ & $\mathrm{~K}$ & $S$ & $\mathrm{Ca}^{2+}$ & $\mathrm{Mg}^{2+}$ \\
\hline & $\mathrm{g} \mathrm{Kg}^{-1}$ & & $\mathrm{CaCl}_{2}$ & & $\mathrm{mg} \mathrm{dm}^{-3}$ & & \multicolumn{2}{|c|}{$\mathrm{C} \mathrm{mol} \mathrm{dm}{ }^{-3}$} \\
\hline Média & 461,2 & 20,3 & 4,8 & 7,4 & 36,5 & 12,7 & 1,6 & 0,7 \\
\hline Máximo & 587 & 25,4 & 4,9 & 15,4 & 55,4 & 24,3 & 2,2 & 1,1 \\
\hline Mínimo & 365 & 17,5 & 4,5 & 1,4 & 22,3 & 7,7 & 0,5 & 0,8 \\
\hline \multirow[t]{3}{*}{$C V(\%)$} & 14,2 & 9,9 & 2,2 & 47,2 & 20,8 & 32,3 & 22,3 & 12,2 \\
\hline & $\mathrm{Al}^{2+}$ & $\mathrm{H}+\mathrm{Al}$ & $\mathrm{T}$ & $\mathrm{Zn}$ & $\mathrm{Cu}$ & $\mathrm{Fe}$ & $\mathrm{Mn}$ & B \\
\hline & \multicolumn{2}{|c|}{$\mathrm{C} \mathrm{mol} \mathrm{dm} \mathrm{m}^{-3}$} & \multicolumn{6}{|c|}{$\mathrm{Mg} \mathrm{dm}^{-3}$} \\
\hline Média & 0,1 & 4,4 & 7,6 & 3,6 & 1,2 & 181,2 & 7,7 & 0,2 \\
\hline Máximo & 0,4 & 5,3 & 8,4 & 8,8 & 1,8 & 346,7 & 17,6 & 0,5 \\
\hline Mínimo & 0 & 3,8 & 6,2 & 0,5 & 0,5 & 97,8 & 3,3 & 0,1 \\
\hline CV(\%) & 100 & 10,5 & 8,6 & 33,4 & 33,7 & 37,2 & 46,5 & 37,6 \\
\hline
\end{tabular}

'Nota: Argila (método gravimétrico): MO (1.72x teor de carbono determinado pelo método da oxidação com dicromato de potássio em meio ácido): pH (CaCl2 0,01 mol L-1, relação 1:2,5); P, K e micronutrientes (Mehlich-1, relação 1:10); $\mathrm{Ca}_{2}+\mathrm{Mg}_{2}+\mathrm{e} \mathrm{Al}_{3}+\left(\mathrm{KCl}^{1} \mathrm{~mol} \mathrm{L-1}\right.$, relação 1:10); H + Al (acetato de cálcio $0,5 \mathrm{~mol} \mathrm{~L}^{-1}, \mathrm{pH} 7,0$ ). 
de I. cordifolia foram semeadas numa profundidade de $\pm 1,0 \mathrm{~cm}$ (Prates et al., 2000). As concentrações de 0,$25 ; 5$ e $10 \mathrm{~g}$ do pó seco e moído das raízes e folhas de $A$. extraaxillaris foram pesadas e colocadas em cima do solo. Os vasos foram mantidos em casa de vegetação e irrigados diariamente com água destilada, baseando-se no índice de retenção de $80 \%$ (Brasil, 2009). O número de plântulas emersas em cada vaso também foram anotados diariamente, e após 30 dias de cultivo as plantas foram colhidas.

Parte das plantas (cerca de 3 indivíduos de cada vaso) foram congeladas e levadas para laboratório, com a finalidade de avaliar o estresse oxidativo da parte aérea. As demais plantas foram separadas para avaliação do comprimento $(\mathrm{cm})$ da parte aérea e da raiz, sendo essas levadas para secar em uma estufa $a 0^{\circ} \mathrm{C}$ até peso constante para a obtenção da massa seca, em gramas (Ninkovic, 2003).

O delineamento experimental usado foi o de blocos casualizados com três concentrações e um controle $(0 ; 0,25 ; 5$ e $10 \mathrm{~g})$, em quatro repetições. Cada parcela constituiu-se de dez sementes para emergência e crescimento. Foi calculado o Índice de Velocidade de Emergência (IVE) [IVE $=\Sigma\left(G_{i} /\right.$ $N_{i}$ )] (Onde $G_{i}$ é o numero de plântulas emersas no intervalo de tempo $t_{i-1} \leftrightarrow t_{i}$ e $N_{i}$ é o número de dias após a semeadura) e a porcentagem de plântulas emersas $(E \%)\left[E \%=\left(\Sigma n_{i} \cdot N^{-1}\right) .100\right]$ (onde $n_{i}$ é o numero de plântulas emersas no intervalo de tempo $t_{i-1} \leftrightarrow t_{i}$ e $N$ é o número de sementes usadas em cada tratamento).

$\mathrm{Na}$ análise do estresse oxidativo, foram medidas as atividades da catalase, peroxidase, superóxido dismutase, glutationa redutase, peroxidação lipídica e síntese de formazan (respiração). A atividade da catalase foi medida em um meio contendo $67 \mathrm{mM}$ de tampão fosfato de potássio $(\mathrm{pH} 7,0), \mathrm{H}_{2} \mathrm{O}_{2}(10 \mathrm{mM})$, e 0,1-0,4 mg de proteína do extrato enzimático. $\mathrm{O}$ consumo de $\mathrm{H}_{2} \mathrm{O}_{2}$ foi monitorado a $240 \mathrm{~nm}\left(\varepsilon, 0,036 \mathrm{mM}^{-1} \mathrm{~cm}^{-1}\right)$ (Aebi, 1984).

A atividade da peroxidase (POD) foi medida em um meio contendo tampão fosfato de Potássio $25 \mathrm{mM}(\mathrm{pH} 6,8), \mathrm{H}_{2} \mathrm{O}_{2}(10 \mathrm{Mm})$ guaiacol $(2,6 \mathrm{mM})$ e 0,1-0,4 mg de proteína do extrato enzimático. A formação de Tetraguaicol $\left(\varepsilon, 25,5 \mathrm{mM}^{-1} \mathrm{~cm}^{-1}\right)$ foi monitorada a $470 \mathrm{~nm}$ (Putter, 1974).

Atividade de superóxido dismutase (SOD) foi medida de acordo com Giannopolitis \& Ries (1977). O meio continha tampão fosfato de potássio50 mM (pH 7,8) e L- metionina $6,5 \mathrm{mM}$, nitroblue tetrazolium $150 \mathrm{uM}$, riboflavina $4 \mu \mathrm{M}$ e $0,02-0,1 \mathrm{mg}$ de proteína do extrato enzimático. A reação foi iniciada pela ativação de uma luz (20 W) e iluminando o meio durante 20 minutos a $30^{\circ} \mathrm{C}$. Uma unidade de atividade de SOD (U) foi definida como a quantidade de enzima necessária para causar uma inibição de $50 \%$ da taxa de fotoredução (NBT) a $560 \mathrm{~nm}$, e os resultados foram expressos como unidades de SOD. $\mu$ g. proteína-1 ${ }^{-1}$.

A atividade da glutationa redutase foi medida num meio contendo tampão fosfato de potássio $50 \mathrm{mM}(\mathrm{pH} 8,0)$, EDTA $2 \mathrm{mM}$, GSSG 0,5 $\mathrm{mM}, \mathrm{NADPH} 0,15 \mathrm{mM}$, e 0,1-0,4 mg de proteína do extrato enzimatico. A taxa de oxidação do NADPH foi monitorizada a $340 \mathrm{~nm}\left(\varepsilon, 6,2 \mathrm{mM}^{-1} \mathrm{~cm}^{-1}\right)$ (Foyer \& Halliwell, 1976).

A peroxidação lipídica foi medida num meio contendo $0,1 \%$ de ácido tricloroacético, $0,5 \%$ de ácido tiobarbitúrico e 0,1-0,4 mg de proteína do extrato enzimatico (Gomes-Júnior et al., 2006). No momento da leitura, as amostras foram centrifugadas a $20.000 \mathrm{rpm}$ durante 5 minutos e a absorbância do sobrenadante foi lida a $534 \mathrm{~nm}$ e a atividade expressa como percentagem do estímulo de peroxidação lipídica.

As atividades das enzimas foram calculadas segundo Bracht et al., 2003. Para todas as enzimas descritas, foi acrescentado o extrato enzimático, com os reagentes específicos para cada atividade avaliada. A absorbância dessas amostras foi monitorada durante 0 a 9 minutos, e em seguida plotado um gráfico para cada dosagem enzimática, para obtenção da variação da tangente $[\alpha \operatorname{tg}=\Delta \mathrm{A} /$ $\Delta \mathrm{t}$ ] (onde: $\Delta \mathrm{A}=\mathrm{a}$ variação da absorbância; $\Delta \mathrm{t}=\mathrm{a}$ variação do tempo em minutos). Após as leituras das absorbâncias das enzimas, a atividade foi calculada em $\mu \mathrm{mol}$. min $^{-1}$ [Atividade $\left(\mu \mathrm{mol} \mathrm{min}{ }^{-1}\right)=$ vol de incubação $x \alpha \operatorname{tg}\left(\min ^{-1}\right) / \varepsilon=$ unidades de enzima] (onde: $\varepsilon=$ Coeficiente de extinção molar da enzima)

A respiração potencial das células radiculares foi estimada por meio da redução do cloridrato de trifenil tetrazólio (TTC). As raízes foram cortadas a $1,0 \mathrm{~cm}$ a partir da coifa, pesadas $(20 \mathrm{mg})$ e transferidas para tubos de ensaios e adicionados $3,0 \mathrm{~mL}$ de TTC $0,6 \%$ (p/v) em tampão fosfato $0,05 \mathrm{M}(\mathrm{pH} \mathrm{7,0)}$. Os tubos foram mantidos sob vácuo em dessecador, por 2 horas, e em seguida transferidos para banho-maria a $30^{\circ} \mathrm{C}$ por 15 horas. Ao final desse tempo, as soluções de TTC foram drenadas dos tubos e as raízes lavadas uma vez com água destilada. Os tubos de ensaios contendo as raízes foram novamente transferidos para banho-maria $\left( \pm 100^{\circ} \mathrm{C}\right)$, e adicionados $7 \mathrm{~mL}$ de etanol $95 \%(v / v)$. Decorridos 10 minutos as soluções etanólicas foram drenadas e após o resfriamento, cada solução foi acrescida de $10 \mathrm{~mL}$ de etanol $95 \%$ (v/v), e as absorbâncias lidas em espectrofotômetro, no comprimento de onda $530 \mathrm{~nm}$ (Steponkus \& Lanphear, 1967).

Os dados foram submetidos à análise de variância e quando os efeitos dos tratamentos foram significativos, $(p<0,05)$, em relação à testemunha, as

Rev. Bras. PI. Med., Campinas, v.18, n.1, supl. I, p.215-222, 2016. 
médias foram comparadas pelo teste de Dunnet. Os resultados apresentados nas tabelas correspondem a Média \pm desvio padrão, e nos gráficos, os resultados são representados em porcentagem em relação ao controle, sendo que o zero representa o controle, valores positivos representam estímulo e valores negativos representam inibição (Macias et al., 2006).

\section{RESULTADOS E DISCUSSÃO}

As concentrações de 5 e $10 \mathrm{~g}$ das folhas de Asemeia extraaxillaris atrasaram a emergência de Ipomoea cordifolia, com IVE igual a 0,48 e 0,41 , respectivamente. Para as raízes esse atraso ocorreu em todas as concentrações, e de acordo os valores obtidos para IVE é evidente que as sementes de I. cordifolia apresentaram maior sensibilidade para raízes (IVE igual a 0,42; 0,40 e 0,37 respectivamente). Na porcentagem final de plântulas emersas, foi verificado um mesmo efeito nas plântulas tratadas com lixiviados das folhas e raízes como demonstrado na tabela 2 .

O IVE e porcentagem de emergência das plântulas do controle apresentaram baixa germinabilidade e porcentagem de emergência. Este fato pode ser decorrente das oscilações de temperatura que ocorrem em Curitiba. Além disso, um estudo realizado sobre as condições de temperatura na germinação das espécies de I. grandifolia, I. nil demonstrou que estas podem apresentar taxa de germinação entre 9 e 16 em condições de temperatura iguais a 15 a $20^{\circ} \mathrm{C}$ (Orzari et al., 2013).

Alterações no crescimento das plantas também foram observados para a raiz primária. Todas as concentrações das folhas e raízes de A. extraaxillaris inibiram o crescimento das raízes de $I$. cordifolia e a concentração de $10 \mathrm{~g}$ inibiu o crescimento em $50 \%$ (figura $1 \mathrm{~A}$ ). No crescimento do hipocótilo, foi observada uma redução de $56 \%$ (concentração de $10 \mathrm{~g}$ ) (figura $1 \mathrm{~B}$ ). A diminuição na massa seca das plantas de I. cordifolia também foi observada para as concentrações de 5 e $10 \mathrm{~g}$, com efeitos inibitórios mais pronunciados de $57.3 \%$ e $42.1 \%$ para raízes e folhas, na concentração de $10 \mathrm{~g}$ (figura 1C). Silva et al. (2013) demonstraram que em condições de laboratório, o óleo volátil presente nas raízes de $A$. extraaxillaris reduziram a germinação de $B$. decumbens em $52 \%$ e $58 \%$ em relação ao controle. Mudanças nos padrões de germinação podem resultar de vários efeitos à níveis primários (Gusman et al., 2008). Entre eles, podem ser citados alterações na permeabilidade da membrana, transcrição e tradução celular, processo respiratório, expressão de enzimas e receptores, ou mesmo a combinação de todos estes aspectos (Ferreira \& Aquila, 2000).

Segundo Macias et al. (2000), os sistemas vivos apresentam uma grande variabilidade na sua resposta aos tratamentos, e um único agente pode induzir efeitos em diferentes espécies para maior confiabilidade dos resultados e observação de algum efeito seletivo. As diferentes partes morfológicas aqui investigadas com potencial alelopático demonstram que são efetivos no controle de I. cordifolia, e que tal efeito pode ocorrer pela lixiviação de substâncias presentes em A. extraaxillaris. Silva et al. (2013) identificaram a substância 1-(2-hidroxifenil)-etanona nas raízes de $A$. extraaxillaris, e levantaram a hipótese de que esta substância pode estar atuando como agente alelopático.

Os efeitos inibitórios foram proporcionais à quantidade de material utilizado, demonstrando que existe uma relação dose-dependente, com aumento de atividade proporcional ao aumento da concentração. Nos estudos alelopáticos, geralmente a bioatividade tende a exibir um padrão dose-resposta, ou seja, a inibição observada é dependente da concentração de aleloquímicos disponíveis, com isso os compostos tendem a agir como inibidores em concentrações mais elevadas e essa atividade tende a diminuir com a diluição (Macias et al., 2000).

$\mathrm{Na}$ avaliação do estresse oxidativo, houve aumento na atividade da catalase nas maiores

TABELA 2. Efeito de diferentes concentrações dos lixiviados das raízes e folhas de Asemeia extraaxillaris sobre o índice de velocidade de emergência (IVE) e porcentagem de emergência (\%E) de Ipomoea cordifolia.

\begin{tabular}{cccccc}
\hline \multicolumn{2}{c}{ Índice de velocidade de emergência (IVE) } & \multicolumn{3}{c}{$\%$ de emergência (\%E) } \\
\hline $\mathbf{n}=\mathbf{4}$ repetições & raízes & folhas & $\mathbf{n}=\mathbf{4}$ repetições & raízes & folhas \\
Controle & $0,56 \pm 0,17$ & $0,56 \pm 0,17$ & Controle & $67,9 \pm 3,4$ & $67,9 \pm 3,4$ \\
$0,25 \mathrm{~g}$ & $0,42 \pm 0,13^{*}$ & $0,51 \pm 0,14^{\text {ns }}$ & $0,25 \mathrm{~g}$ & $63,4 \pm 2,19^{*}$ & $66,7 \pm 1,17^{\text {ns }}$ \\
$5 \mathrm{~g}$ & $0,40 \pm 0,09^{*}$ & $0,48 \pm 0,17^{*}$ & $5 \mathrm{~g}$ & $58,7 \pm 1,21^{*}$ & $61,3 \pm 1,76^{*}$ \\
$10 \mathrm{~g}$ & $0,37 \pm 0,16^{*}$ & $0,41 \pm 0,03^{*}$ & $10 \mathrm{~g}$ & $53,4 \pm 2,31^{*}$ & $59,2 \pm 1,26^{*}$ \\
\hline
\end{tabular}

Nota: Resultados expressos em média desvio padrão. *A média do tratamento difere significativamente $(p<0,05)$ em comparação com a média do controle, pelo teste de Dunnet. nsA média do tratamento não difere significativamente da média do controle.

Rev. Bras. PI. Med., Campinas, v.18, n.1, supl. I, p.215-222, 2016. 


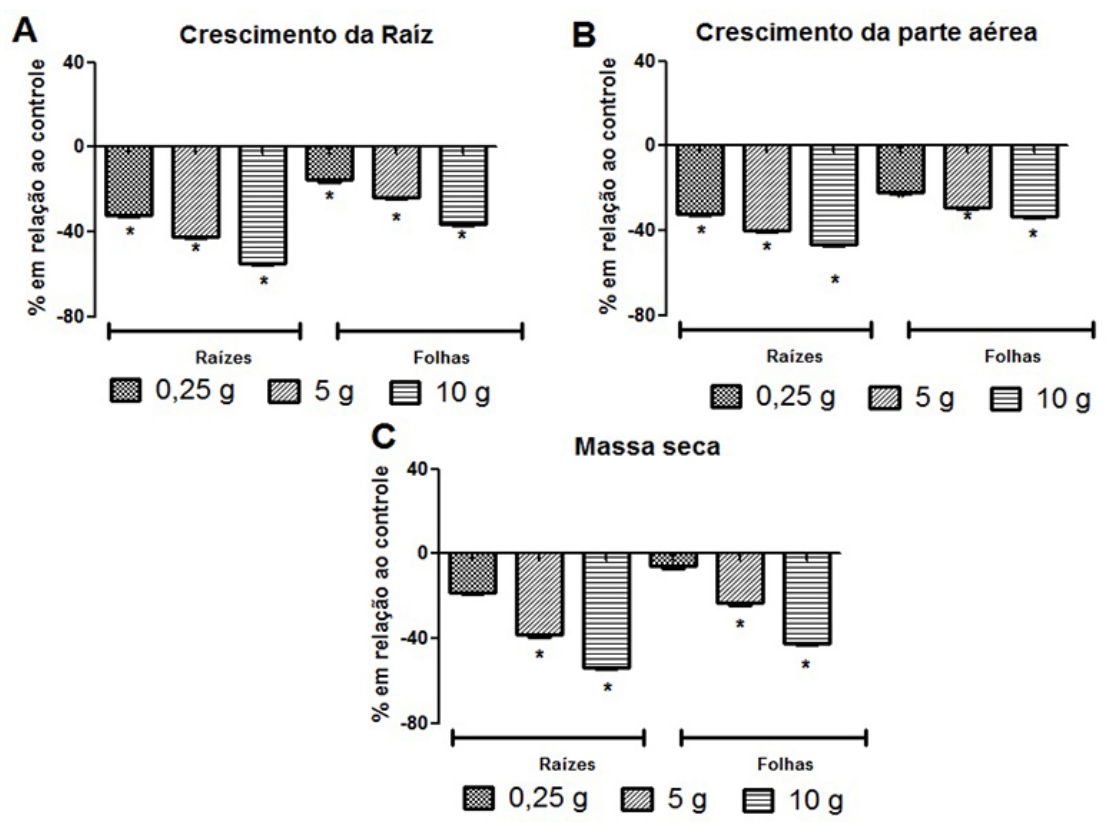

FIGURA 1. Efeito das diferentes concentrações dos lixiviados das raízes e folhas de $A$. extraaxillaris sobre o crescimento da raiz, hipocótilo e massa seca de I. cordifolia. Dados expressos em percentual em relação ao controle. *A média do tratamento difere significativamente em comparação com a média do controle, pelo teste de Dunnet.

concentrações ensaiadas com lixiviados das folhas e raízes de $A$. extraaxillaris, e uma maior atividade foi

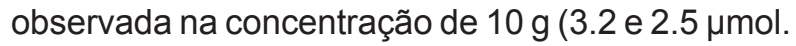
min-1 $^{-1}$ para raízes e folhas, respectivamente) (figura $2 \mathrm{~A})$. Resultados semelhantes foram obtidos para a peroxidase. Entretanto, a concentração de $0,25 \mathrm{~g}$ não aumentou a produção da peroxidase (figura 2 B). A análise da atividade da superóxido dismutase, mostra o aumento dependente da concentração utilizada para os lixiviados das raízes (2.8; 3.2 e $4.9 \mu \mathrm{mol}$. min-1 $^{-1}$ para as concentrações de $0.25,5$

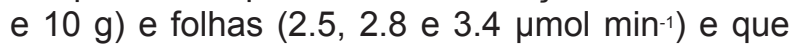
I. cordifolia é mais sensível aos aleloquímicos das raízes (figura $2 \mathrm{C}$ ).

A comparação das atividades das enzimas ensaiadas revelam que a peroxidase e superóxido dismutase provavelmente são as principais enzimas antioxidantes envolvidas na eliminação de espécies reativas de oxigênio em em I. cordifolia durante o crescimento. A catalase, pode estar atuando como enzimas acessória neutralizando $\mathrm{H}_{2} \mathrm{O}_{2}$, implicando numa vasta gama de processos fisiológicos (Passardi et al., 2005). Peroxidases podem ligar-se a polímeros da parede celular por interações iónicas ou covalentes, podendo participar no processo de biossíntese de lignina e na formação de ligações cruzadas na parede da célula (Müsel et al., 1997; Quiroga et al., 2000).

A produção de glutationa redutase também demonstrou ser afetada pelos lixiviados de A. extraaxillaris. Um aumento dose dependente também foi observado, com maior produção para os lixiviados das raízes $\left(3.7 \mu \mathrm{mol} \mathrm{min}^{-1}\right)$ e folhas $\left(3.3 \mu \mathrm{mol} \mathrm{min}{ }^{-1}\right)$ na concentração de $10 \mathrm{~g}$. A menor concentração das folhas não estimulou a produção da glutationa redutase (figura $2 \mathrm{D}$ ).

Nas plantas tratadas com lixiviados das raízes, a peroxidação lipídica também aumentou em função da concentração utilizada, com estímulo de $39,2 \%$ e $42 \%$ nas concentrações de 5 e 10 $\mathrm{g}$, respectivamente. Os lixiviados das folhas apresentaram menor estímulo, com valores de $28,3 \%$ na concentração de $5 \mathrm{~g}$ e $38,4 \%$ na concentração de $10 \mathrm{~g}$. A concentração de $0,25 \mathrm{~g}$ não provocou estimulo nas plantas tratadas com lixiviados das folhas e raízes (Figura $3 \mathrm{~A}$ ). Os lixiviados das folhas e raízes também aumentaram a síntese de formazan em plantas de I. cordifolia, com maior atividade para a concentração de $5 \mathrm{~g}$ (0.362 $\mathrm{nm}$ para folhas, e $0,233 \mathrm{~nm}$ para raízes). A menor concentração não alterou a concentração final de formazan, quando comparada ao controle (figura 3 B).

A literatura reporta que alguns aleloquímicos rapidamente despolarizam as membranas das células, aumentando sua permeabilidade e induzindo a peroxidação de lipídeos, causando um distúrbio celular generalizado que pode levar à morte das células (Yu et al., 2003). Existem estudos que demonstram o aumento na taxa de peroxidação lipídica e a taxa respiratória durante o desenvolvimento de plantas (Staniek \& Nohl, 2000). 

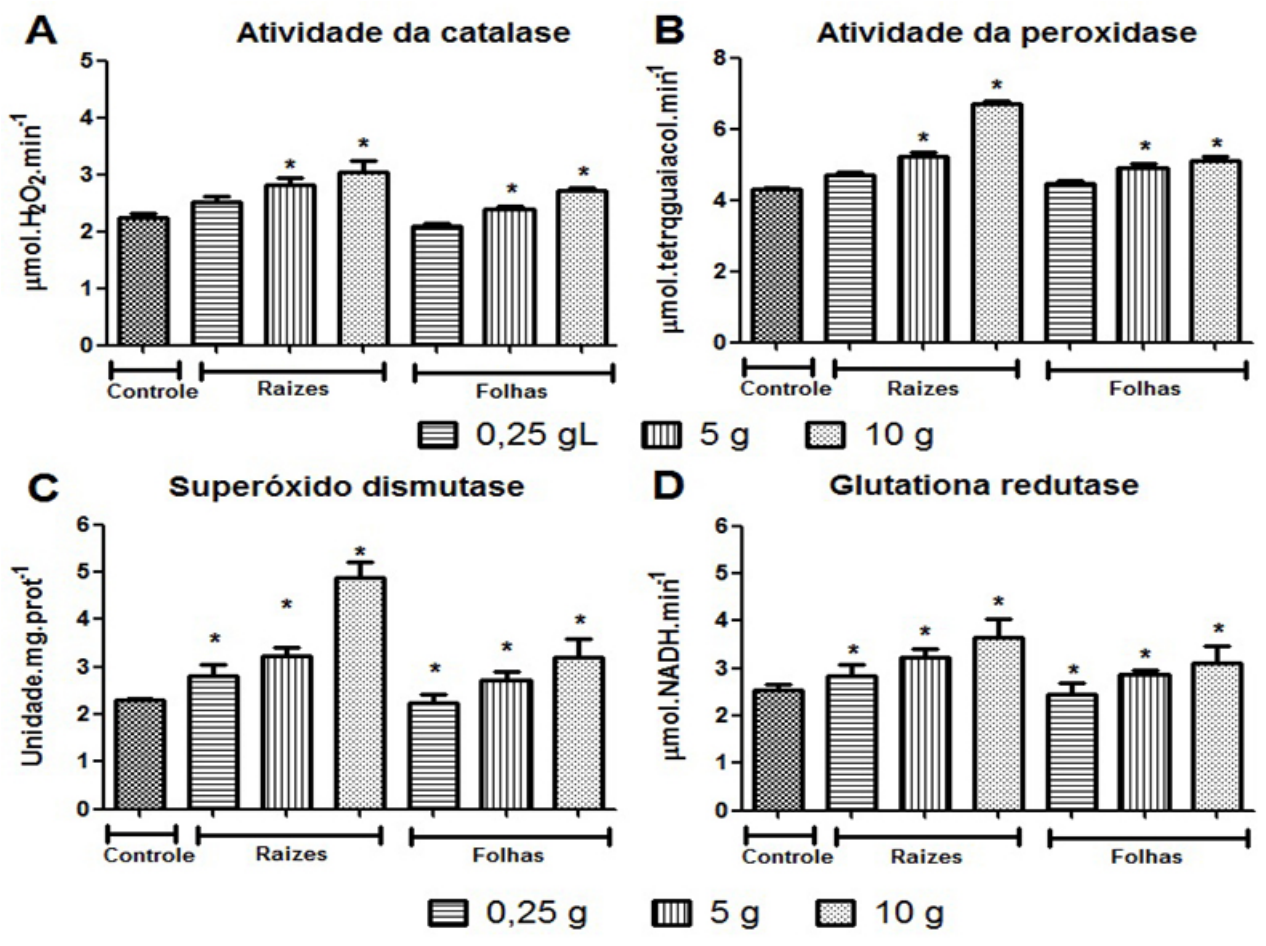

FIGURA 2. Efeito das diferentes concentrações dos lixiviados das raízes e folhas de $A$. extraaxillaris sobre a catalase $(A)$, peroxidase $(B)$, superóxido dismutase $(C)$ e glutationa redutase (D). Dados expressos em percentual em relação ao controle. *A média do tratamento difere significativamente em comparação com a média do controle, pelo teste de Dunnet.

Os herbicidas inibidores do FS II, entre eles o metribuzin, exercem sua ação herbicida inicialmente pelo bloqueio do fluxo de elétrons do FS II. Esse bloqueio impede a transferência de energia da clorofila para o centro de reação $P_{680}$, 0 que dá origem a uma clorofila altamente reativa, a clorofila tripleto $\left({ }^{3} \mathrm{Chl}\right)$. Esta clorofila reage com o oxigênio molecular, gerando espécies reativas de oxigênio (EROs). Todas essas moléculas altamente reativas irão reagir com os lipídios formadores das membranas, originando a peroxidação lipídica, que, além de formar novos radicais lipídicos, danificam irreversivelmente as membranas celulares (Hess, 2000; Fleck \& Vidal, 2001).

Desse modo, sugere-se que o aumento na taxa de peroxidação lipídica podem ocorrer como conseqüência de distúrbios nas membranas celulares (Song et al., 1996), alterando a permeabilidade, levando a destruição dos cloroplastos, mitocôndrias, núcleo e retículo endoplasmático. Esses processos fisiológicos anormais resultam na redução da fotossíntese bem como no aumento da respiração, contribuindo para a redução do crescimento das plantas (Almeida et al., 2008).

As substâncias alelopáticas afetam mais de uma função no organismo atingido, dentre eles é conhecida a redução na absorção de nutrientes, alteração nos hormônios de crescimento, inibição da fotossíntese, alterações no processo respiratório acelerando ou diminuindo a respiração, efeitos na síntese de proteínas, alterações na permeabilidade da membrana e inibição da atividade enzimática (Monteiro \& Vieira, 2002). Semelhante a alguns herbicidas comerciais, os aleloquímicos com potencial herbicida são capazes de promover o estresse oxidativo em plantas, aumentando a atividade de enzimas como a peroxidase, catalase e superóxido dismutase (Pandey et al., 2005).

É importante ressaltar que o potencial alelopático da cobertura vegetal depende da quantidade de resíduo vegetal utilizado, do tipo de substância que é liberada no solo e do tipo de plantas daninhas que ali se desenvolvem, o que torna a escolha do material vegetal a ser utilizado de extrema importância, uma vez que, em quantidades similares, há respostas distintas entre as coberturas para uma mesma espécie de planta daninha (Tokura \& Nóbrega, 2006).

Com isso, é possível perceber que os procedimentos experimentais de alelopatia geram contribuições para os estudos de dinâmica entre espécies vegetais e para a elaboração de estratégias alternativas de produção e manejo de culturas (Souza-Filho et al., 2010), através da escolha de espécies que reduzam os custos de produção, da diminuição do uso de defensivos químicos, 


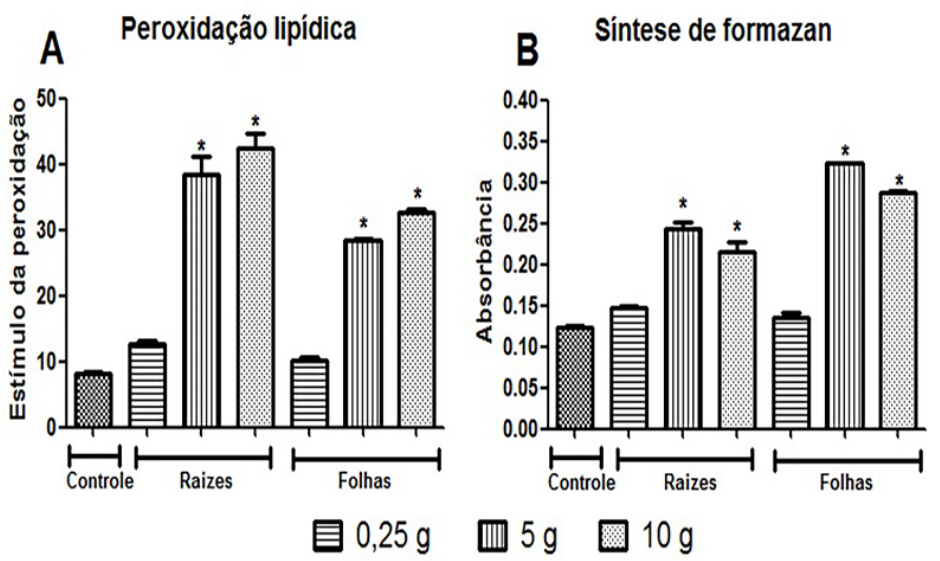

FIGURA 3. Efeito das diferentes concentrações dos lixiviados das raízes e folhas de $A$. extraaxillaris sobre a peroxidação lipídica (A) e sínteze de formazam (B). Dados expressos em percentual em relação ao controle. *A média do tratamento difere significativamente em comparação com a média do controle, pelo teste de Dunnet.

amenizando os impactos que os mesmos causam no ecossistema (Goldfarb et al., 2009), e para a prática de uma agricultura sustentável.

Semelhante a alguns herbicidas comerciais, os aleloquímicos que apresentam potencial para serem utilizados como fitoherbicida são capazes de promover estresse oxidativo em plantas, aumentando a atividade de enzimas como a peroxidase, catalase e superóxido dismutase. Algumas alterações bioquímicas são atribuídas aos aleloquímicos presentes no extrato de Cucumis sativus, como peroxidação de membrana, aumento das enzimas antioxidantes e alterações nas trocas gasosas (Yu et al., 2003). Os resultados obtidos evidenciam que os lixiviados de $A$. extraaxillaris afetam o crescimento de l. cordifolia, com ação inibitória sobre o crescimento, ocasionado pelo aumento no estresse oxidativo.

\section{CONCLUSÃO}

Asemeia extraaxillaris possui ação alelopática sobre corda de viola, interferindo em seu crescimento e levando à um aumento do estresse oxidativo. Lixiviados das raízes de $A$. extraaxillaris se mostraram promissores para posteriores estudos de isolamento, identificação de substâncias químicas e ensaios para verificar o potencial alelopático isolado ou sinérgico dessas substâncias. A identificação destes aleloquímicos pode contribuir para a descoberta de substâncias naturais com potencial fitoherbicida, pois alguns herbicidas comerciais causam a morte celular e induzem ao estresse oxidativo.Este estudo demonstra que esta espécie utilizada pela medicina popular pode ser utilizada como um método não químico de proteção fitossanitária para reduzir o impacto de herbicidas no meio ambiente.

\section{AGRADECIMENTOS}

Os autores agradecem à Capes/UFPR, pela concessão de bolsas e auxílio financeiro.

\section{REFERÊNCIAS}

$\mathrm{AEBI}, \mathrm{H}$. Catalase in vitro. Methods Enzymology, v.105, n.2, p.121-126, 1984.

ALMEIDA, G. D. de; et al., Estresse oxidativo em células vegetais mediante aleloquímicos. Revista Facultad Nacional de Agronomia, v. 61, n. 1, p. 4237-4247, 2008.

BRACHT, A.; SUZUKI- KEMMELMEIER, F.; SALGUEIROPAGADIGORRIA, C.L.; CONSTANTI, J.; YAMAMOTO, N.S.; ISHII- IWAMOTO, E.L. Enzimas. In: BRACHT, A.; ISHII- IWAMOTO, E.L. Métodos de laboratório em Bioquímica: Manuais de laboratório. $1^{\text {a }}$ ed, Barueri: Manole, 2003, p. 103-138.

BRASIL. Ministério da Agricultura e Reforma Agrária. Regras para a Análise de Sementes, SNDA/DNDU/ CLU, $2^{\circ}$ ed. Brasília, 2009, 365 p.

FERREIRA, A.G.; AQUILA, M.E.A. Alelopatia: uma área emergente da ecofisiologia. Revista Brasileira de Fisiologia Vegetal, v. 12, p. 175-204, 2000.

FLECK, N. G.; VIDAL, R. A. Herbicidas inibidores do fotossistema 2. In: VIDAL, R. A.; MEROTTO Jr., A. (Eds.). Herbicidologia: um guia de estudo. $1^{\text {a }}$ ed., Porto Alegre: Evangraf, 2001. p. 100-112.

FOYER, C.H.; HALLIWELL, B. The presence of glutathione and glutathione reductase in chloroplasts: a proposed role in ascorbic acid metabolism. Planta, v. 133, p. 21-25, 1976.

GIANNOPOLITIS, C.N.; RIES, S.K. Superoxide dismutases: occurrence in higher plants. Plant Physiology, v. 59, p. 309-314, 1977.

GOLDFARB, M.; et al., Alelopatia: relações nos agroecossistemas. Tecnologia \& Ciência Agropecuária, v. 3, n. 1, p. 23-28, 2009.

GOMES-JÚNIOR, R.A.; et al., Antioxidant metabolism of coffee cell suspension cultures in response to cadmium. 
Chemosphere, v. 65, p. 1330-1337, 2006.

GUSMAN, G.S. et al., Alelopatia de Baccharis dracunculifolia DC. sobre a germinação e desenvolvimento de espécies cultivadas. Acta Scientiarum Biological Science, v.30, p.119-125, 2008.

HESS, F. D. Light-dependent herbicides: an overview. Weed Science, v. 48, p. 160-170, 2000.

HOLM, L., DOLL, J., HOLM, E., PANCHO, J., HERBERGER, J. $1^{\text {a }}$ ed., World weeds, natural histories and distribution. New York, USA: Wiley one library, 1997, $1129 \mathrm{p}$.

LÜDTKE, R.; AGUIAR, A. C. A. Nota sobre a ocorrência de pétalas reduzidas em espécies de Polygala L. subgênero Hebeclada (Chodat) Blake (Polygalaceae) da Região Sul do Brasil. Biota Neotropica, v. 8, n. 1, p. 239-242, 2008.

MACIAS, F.A., et al., Search for a standart phytotoxic biossay for allelochemicals. Selection of standard target species. Journal Agricultural and Food Chemistry, v. 48, n. 6, p. 2512-2521, 2000.

MACIAS, F.A.; et al., Sesquiterpene Lactones as Allelochemicals. Journal of Natural Products, v. 69, n.1, p. 795-800, 2006.

MONTEIRO, C. A.; VIEIRA, E. L. Substâncias alelopáticas. In: CASTRO, P. R. C.; SENA, J. O. A.; KLUGE, R. A. Introdução à fisiologia do desenvolvimento vegetal. $1^{\text {a }}$ ed. Maringá: EDUEM, 2002, p. 79-104.

MÜSEL, G.; et al., Structure and distribution of lignin in primary and secondary cell walls of maize coleoptiles analyzed by chemical and immunological probes. Planta, v. 201, p.146-159, 1997.

NINKOVIC, V. Volatile communication between barley plants affects biomass allocation. Journal of Experimental Botany, v. 54, p. 1931-1939, 2003.

NISHIMURA, H., et al., Allelopathic effects of p-methane3,8-diols in Eucalyptus citriodora. Phytochemistry, v. 23, p. 2777-2779, 1984.

OLIVEROS-BASTIDAS, A. J.; et al., Exudados de la raiz y su relevancia actual en las interacciones alelopáticas. Química Nova, v. 32, p. 198-213, 2009.

ORZARI, I.; et al., Germinação de espécies da família Convolvulaceae sob diferentes condições de luz, temperatura e profundidade de semeadura. Planta daninha. v.31, p. 53-61, 2013.

PANDEY, D.K.; et al., Relative phytotoxicity of hydroquinone on rice (Oryza sativa L.) and aquatic weed green musk chara (Chara zeylania WIIld). Pesticide Biochemistry and Physiology, v. 83, p, 82- 96, 2005.

PIRES, N. M.; et al., Atividade alelopática da leucena sobre espécies de plantas daninhas. Scientia Agrícola, v. 58, p. 61-65, 2001.

PASSARDI, F.; et al., Peroxidases have more function than a Swiss army knife. Plant Cell Report, v. 24, p.255-265, 2005.

POTT, A; POTT, V. J. Plantas do pantanal. $2^{\mathrm{a}}$ ed, Corumbá: EMBRAPA - SPI, 1994, 320 p.

PRATES, H.T.; et al., Efeito do extrato aquoso de Leucena na germinação e no desenvolvimento do milho. Pesquisa Agropecuária Brasileira, v. 35, p. 909-914, 2000.

PUTTER, J. Peroxidase. In: BERGMEYER, H. U. (ed.). Methods of Enzymatic Analysis. $2^{\mathrm{a}}$ ed. Verlag Chemie: Weinhan, 1974, p. 286-293.

QUIROGA, M.; et al., A tomato peroxidase involved in the synthesis of lignin and suberin. Plant Physiology, v. 122, p.1119-1128, 2000.

SILVA, C.B. et al., Polygala extraaxillaris: oxidative stress in Brachiaria decumbens mediated by volatile oils. Planta daninha, v. 31, p. 793-804, 2013.

SONG, F.M.; et al., Role of active oxygen and membrane lipid peroxidation in plant pathogegen interactions. Plant Physiology Communications, v. 32, p. 377385,1996.

SOUZA-FILHO, A. P. da S.; et al., Metodologias empregadas em estudos de avaliação da atividade alelopática em condições de laboratório - revisão crítica. Planta Daninha, v. 28, n. 3, p. 689-697, 2010.

STANIEK, K.; NOHL, H. Are mitochondria a permanent source of reactive oxygen species? Biochimica et Biophysica Acta, v.1460, p.268-275, 2000.

STEPONKUS, P. L.; LANPHEAR, F. O. Refinement of the triphenyl tetrazolium chloride method of determining cold injury. Journal of Plant Physiology, v.42, n.1, p.1423-1426, 1967.

TOKURA, L. K.; NÓBREGA, L. H. P. Alelopatia de cultivos de cobertura vegetal sobre plantas infestantes. Acta Scientiarum Agronomy, v. 28, n. 3, p. 379-384, 2006.

YU, J.Q.; et al., Effects of root exudates and aqueous extracts of cucumber (Cucumis sativus) and allelochemicals, on photosynthesis and antioxidant enzymes in cucumber. Biochemical Systematics and Ecology, v. 31, p. 129-139, 2003.

Rev. Bras. PI. Med., Campinas, v.18, n.1, supl. I, p.215-222, 2016. 